\title{
"Natural Relations": A Note on X'-Structure"
}

\section{Introduction}

With the rise of minimalism, many concepts related to the geometrical relations of phrase structure held fast to in earlier approaches have been reconsidered. This article deals with distinguishing (relational and technical) properties of specifiers and adjuncts in a Bare Phrase Structure framework ( $\mathrm{X}^{\prime}$-Theory). I extend specific aspects of $\mathrm{X}^{\prime}$-structure relevant to the discussion of specifiers vs. adjuncts. I argue that unique specifiers can be derived from the system and that adjunction, possibly multiple, results from Direct Merge only. The final product is a series of relationships in line with recent thoughts and minimalist premises, but formally more similar to earlier conceptions of the X'-schema.

I address conceptual, empirical and theoretical arguments against multiple specifiers and related issues next, that is beyond the predictions immediately following from the tripartitional view of clause structure proposed in Grohmann (2000). After laying out my motivations to critically consider the issue, I present a set of data that casts serious doubt over the justifications offered to replace Agr with $v$ as the accusative casemarker. Having conceptual and empirical back-up, I then tackle the theoretical validity of specifiers, and ways to distinguish unique specifiers from (multiple) adjuncts. I introduce a version of Bare Phrase Structure that does so, yet keeps the spirit of defining structural identification over relational rather than categorial properties.

\section{Basic Background}

I will start by presenting a brief overview of the issues relevant to the following discussion. We will first see how adjuncts and specifiers are traditionally understood, what

\footnotetext{
I am very pleased to express part of my thanks and gratitude to Ewald, a dear friend and colleague. The present contribution is a slightly modified version of the first part of my dissertation's chapter 3 (Grohmann 2000). I believe-or at least, hope-that it is sclf-contained and coherent, even without the background of the theoretical framework sketched in the original work, which I can only allude to here. In the program I developed in my dissertation, the relations relevant to $X$ '-structure presented in the present paper play a supporting role, but in the bigger picture the concept of Prolific Domains from my dissertation and the view of $\mathrm{X}^{\prime}$-structural relations defended here are independent of each other. Thus, the following can and should be read as a series of remarks regarding the structural relations expressed by $\mathrm{X}^{\prime}$-Theory from a minimalist point of view. Moreover, as parts of it could be relevant to some of Ewald's work on adjunction-whether he agrees with the views put forth here or not-I am glad to chip in something relevant in content also. Thanks to the editors of this Festschrift to elicit a contribution from me, and for their efforts to sweeten Ewald's departure from the ZAS-director post.
} 
properties are usually ascribed to them, and whether/how they can or even should be distinguished, my main concern in this paper. Then I will introduce the necessary terminology and properties of $X^{\prime}$-structure which will subsequently be modified.

\subsection{Adjuncts vs. Specifiers}

In Bare Phrase Structure Theory - where apparently only minimal and maximal projections (roughly, a non-projecting element and a fully projected phrase) count for interpretation, and intermediate levels of projection (whether we call this recursive projection $\mathrm{X}^{\prime}$ or not fully projected XP) can be formally ignored-we face the problem of integrating one major property of the original $X^{\prime}$-Theory, namely the distinction between specifiers and adjuncts. Intuitively, these entities are different: adjuncts are purely "optional" (not necessarily in the technical sense), while specifiers are obligatory, much like complements, a fact that should ideally be cashed out in terms of Checking Theory.

In this paper, I express why one might want to maintain a structural difference between specifier and adjunct, which basically boils down to the different types of licensing for each: specifiers check matching features with a head, while adjuncts check a feature on themselves. I also present theoretical and empirical arguments against multiple specifiers in general and in favour of (possibly, multiple) adjunction as the result of base-generation only. The empirical evidence from accusative Case-marking in Dutch boils down to the presence of a position which has purely grammatical function; in other words, whether this position is assumed to be an outer Spec $v \mathrm{P}$ or a unique SpecAgrOP does not really matter-what matters is that the original motivation to dispense with AgrP is lost: if AgrP only has grammatical function, while $v P$ has other intrinsic properties (interpretable $\theta$-features), then something should be amiss if we encounter evidence suggesting that there are instances when $v \mathrm{P}$ would play no role other than marking accusative case. Finally, I suggest a technical implementation in terms of "most natural" (meaning basic) relations which, moreover, come free with the operation Merge: sisterhood and immediate containment. I lay out how (the composition of) these two relations can be used to force feature checking to take place only between a head and a complement, an adjoined head or a specifier; moreover, it further enforces unique specifiers.

In a nutshell, I modify relational definitions of $\mathrm{X}^{\prime}$-structure, as desired in Bare Phrase Structure Theory (cf. Muysken 1982, Freidin 1992, Chomsky 1994, 1995a). This modification-independently needed, if we take Chomsky's (1998) suggestions of basic relations that Merge yields for "free" and the composition of these seriously-has at least two relevant consequences: (i) multiple specifiers are undesirable, do not buy us much empirically, and can be banned from the grammar, and (ii) specifiers and adjuncts are distinct relational objects, an assumption that can also be built into a definition of X'structure, has a high empirical pay off, yet loses strict asymmetry (pace Kayne 1994).

The proposal of this paper is very strong and makes a number of immediate predictions. In particular, beyond the obvious (that specifiers, but not adjuncts, are unique and that adjunction to XP must be base-generated), it predicts that adjuncts always c-command specifiers. In other words, a left-branch specifier and its head cannot be separated by a left-adjoined adverb. (Chapter 4 of Grohmann 2000 deals with the phenomenon of 
left dislocation structures which receive not only a straightforward analysis, but also support this prediction empirically.)

\section{$2.2 \quad \mathrm{X}^{\prime}$-Structure Considerations}

I start off with first considerations why specifiers and adjuncts could be handled differently. I introduce the basic terminology and concepts used in the remainder. To start with the former, I employ "adjunct" in the sense of a phrasal modifier, usually taken to adjoin to $X^{\prime}$ (adverbs, in the proto-typical case). The $X^{\prime}$ is recursive, and for reasons that become clear soon, I refer to this level as XP, reserving $X^{\prime}$ for the node immediately dominating the head and its complement. None of the claims about specifiers vs. adjuncts pertain to head movement, conceived of standardly, and here as well, as adjunction.

The original formulation of the EPP in Chomsky $(1981,1982)$ said that sentences must have subjects, or in formal terms: SpecTP (to use current labels) must be filled. ${ }^{1}$ It says nothing about the necessity of each sentence having temporal modification expressed by a (possibly null) adjunct of time adjoined to TP. Likewise, with the rise of the Predicate-Internal Subject Hypothesis (e.g. Fukui 1986, Kuroda 1988, Koopman and Sportiche 1991), it became obligatory that a transitive verb have its specifier filled with the external argument; yet it did not postulate obligatory manner specification, to name one typical VP-adjunct. And neither does an interrogative C-head, which in many languages needs to have a Wh-specifier, also demand an adjunct of sorts, expressing interrogativity.

(Basic) X'-Theory (Jackendoff 1977, Stowell 1981, Chomsky 1986) had an elegant way of dealing with specifiers and adjuncts: a specifier is sister to $X^{\prime}$ and daughter of $\mathrm{XP}$, while an adjunct is sister to and daughter of $\mathrm{X}^{\prime}{ }^{2}$ The recursive $\mathrm{X}^{\prime}$-level thus did quite a lot of work, empirically borne out:

(1)

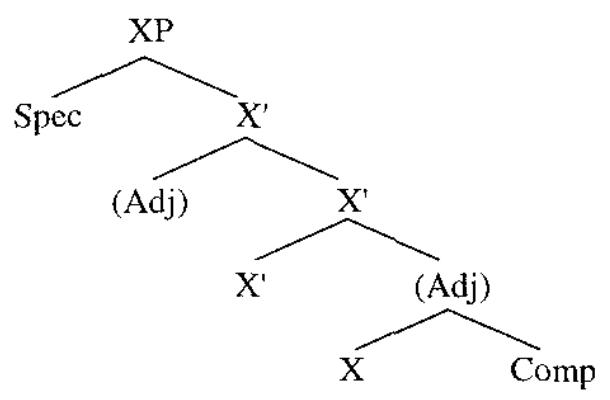

1 A concept which Chomsky (1999) returns to (cf. Lasnik, to appear). That is, after years of trying to motivate the EPP by feature checking, analogously to, say, Casc checking, the current direction suggests a formal implementation of the original idea, that basically forces certain specifier positions to be filled. Whether this is the right approach, or whether other alternatives exist shall not concern us here. On the latter, see, for example, the analysis in terms of predicate raising of Moro (1989, 1997), picked up by Zwart (1992), den Dikken (1995), or a more conservative derivational approach investigated by Epstein and Seely (1999), Castillo, Drury and Grohmann (1997, 1999), Boeckx (2000), Grohmann, Drury and Castillo (2000).

2 Chomsky (1999: 2) expresses similar rclations as primitives: the relations Sister and Immediately Contain come for free. Later on, he also admits that '[l] he conceptual and empirical arguments for $X$ ' invisibility arc slight" (p. 32). I will return to the significance of both in section 4. 
These relations are illustrated in (1). (Adjuncts are parenthesized to indicate their optionality; directionality of projection is not a concern here.) Naturally, this dichotomy did a lot of empirical work, such as define the type of constituent that could be substituted by one $\left(\mathrm{N}^{\prime}\right)$ or so $\left(\mathrm{V}^{\prime}\right)$, account for why adjuncts on the same side of a head may be reordered, but not with respect to complements, and help with other constituency tests. ${ }^{3}$

With the rise of functional projections, especially in the nominal domain (Abney 1987), the role of $X^{\prime}$ became less clear. However, the empirical facts could plausibly be reformulated in terms of a not fully projected XP-level, replacing $\mathrm{X}^{\prime}$. The structural modifications we have to make are obvious (e.g. former SpecNP becomes D ${ }^{0}$ ); I suggest (2) as the relevant $\mathrm{X}^{\prime}$-theoretic object. I do not want to exclude right-adjunction, but will not discuss it further. I will thus defend the following structure:

(2)

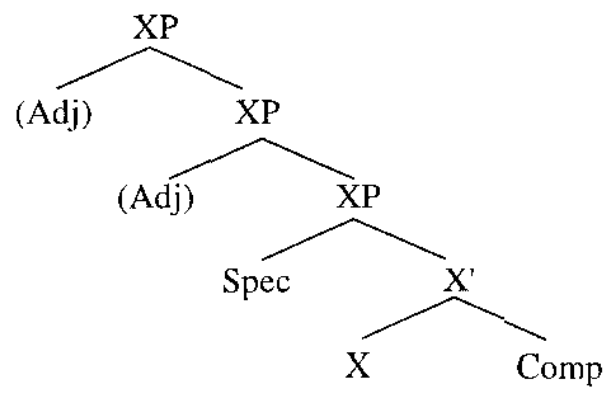

If intermediate levels now do not count anymore (whether X' or XP is taken to be recursive), the distinction between adjuncts and specifiers falling out from (2) is lost and might suggest one of several consequences: maybe specifiers and adjuncts are the same object and there is no distinction, or maybe both/either can have multiple occurrence in a given phrase, or maybe, if both are the same, their occurrence is unique, and so on.

Many maybe's, and each one has been considered: Kayne (1994) argues for collapsing the two notions, understanding each left branch as a unique occurrence of an adjoined element, pushed further by Cinque (1999) from a cross-linguistic perspective and a vast inventory of functional projections (basically, one per left branch); the driving force determining phrase structure is the Linear Correspondence Axiom (LCA) which requires the collapse of the two notions. Lasnik and Saito (1992) argue against adjunction (expressing all relations in terms of substitution). ${ }^{4}$ Chomsky $(1994,1995 a)$

3 As will become clear, I am very sympathetic to the theory of adjunction recently proposed by Ernst (1998, to appear) in terms of Weight Theory-even though space does not permit a more detailed presentation-and as such leave the option of right-adjunction open, if not endorsed. Under this theory, adjuncts are not licensed by checking a formal feature but by certain "LF" properties (regulated by a set of rules for the composition of events, propositions, times and predicates) and "PF" properties (for directionality of adjunction and the weight of adjuncts). In a nutshell, Ernst's theory takes the impact of Full Interpretation seriously in that he considers the alternative to feature checking: if a property of the grammar can only satisfy Full Interpretation by feature checking, the elements in question must enter a checking relationship. But if some other property does not need to check formal features to fulfill Full Interpretation, no checking is required. Adjuncts arguably express properties that do not require formal checking, yet their licensing is driven by the same principles that we employ for all other licensing configurations.

4 Actually, they do not express their proposal quite in these terms. So as to not put words into their mouths, Lasnik and Saito (1992: 87, ex. (81b)) state the condition that "[a]djunction creates a separate maximal projection". 
“proposes" multiple specifiers (drawing from ideas by Koizumi 1994, Ura 1994; see also Ura 1996, Mulders 1996, Richards 1997, 1999 and many others), whose order is determined by certain conditions and adjuncts and specifiers may co-occur in a given phrase (but see fn. 16 below). ${ }^{5}$ Within Bare Phrase Structure, Ernst (to appear) proposes a system that distinguishes specifiers from adjuncts not by force, but in that the latter do not need to check features to satisfy Full Interpretation. As such, the two are different, but no appeal to uniqueness is made, nor needed.

To be honest, I am puzzled by the stipulation-and arguably it is nothing more, as we will see shortly-that intermediate projection levels should be not interpretable at $\mathrm{LF}$ and hence do not count for the computation. If it really is a stipulation, then replacing the stipulation that multiple specifiers are allowed (and intermediate XP-levels invisible to the computation) with another stipulation that bans multiple specifiers from the system should fare equally well. We will see which stipulation does the better work. In the worst case scenario then I assume that multiple specifiers are not part of $\mathrm{C}_{\mathrm{HL}}$ by fiat. But I believe we do not have to go that route. (See also Grohmann 2000: ch. 6.)

\section{On the Interpretability of Agr}

First I will present an empirical argument casting doubt on a hardliner's view that the accusative case checking position must always have other intrinsic properties, then I will address technical issues. In the framework of Chomsky (1995a), multiple specifiers (henceforth, multi-Specs) were employed in three empirical domains of the clause: multi-Specs of $v \mathrm{P}$, of TP, and of CP. The first relate the external argument (agent $\theta$ role) and the object (accusative case) to the same head, $v$-these days adopted in most minimalist scenarios-, while the latter has been applied to multiple fronted Wh-phrases (as in Bulgarian or Romanian; see especially Richards 1997, Bošković 1999, Pesetsky 2000); multi-SpecTP has been argued to be invoked at least in "Multiple Subject Constructions," which are found in Japanese, Korean or Hebrew (Ura 1996, Doron and Heycock 1999), but have also been proposed for Icelandic in the form of Transitive Expletive Constructions (see Chomsky 1995a, drawing from Bobaljik and Jonas 1996).

I will not address the possibility of multi-SpecTP in this paper; mainly, because there are reasons to believe that one of the two "subjects" in these constructions is much more adjunct-like, if not even a topic proper. I will not discuss multi-SpecCP at this point either; see chapter 5 of Grohmann (2000) for a discussion of multiple Whfronting. In the following presentation I concentrate on multi-Specs of $v \mathbf{P}$, going over an empirical counter-argument from Dutch-one that reopens the discussion of the place of Agr in $\mathrm{C}_{\mathrm{HL}}-$, originally due to Zwart (2000). ${ }^{6,7}$

5 See also Nunes and Thompson (1998) for a technical expose on specifiers and adjunction in the "classic" Bare Phrase Structure of the Minimalist Program (drawing on Chomsky 1994, 1995a).

${ }^{6}$ All data in this section are from Dutch and taken straight from Zwart (forthcoming), as is most of the argumentation and mode of presentation, often near-verbatim.

7 The following is not so much a justification of $\mathrm{Agr}$ - or an "explanation" why we might want to have it and why it appears where it appears-, as it is a critique of the one and only argument against Agr: a 


\subsection{Setting the Stage}

Dutch is a West Germanic language with SVO order in subject-initial matrix clauses (and obligatory Verb Second) and SOV in embedded ones. I follow the spirit of Zwart's (1993) analysis: all projections are head-initial and all nominal arguments move out OF their $\theta$-position in overt syntax to check $\phi$-features and get Case-marked. The ensuing debate concerns accusative case. If $V$ is responsible for checking it from some higher functional projection, how far does $\mathrm{V}$ have to raise? There are (at least) two options: $\mathrm{V}$ raises to $v$, which it does anyway, and assigns Case to an outer specifier of $v \mathrm{P}$. Alternatively, the $\mathrm{V}-v$ complex raises to a higher functional projection, call it AgrOP, and assigns Case to Spec of AgrOP.

Chomsky's (1995a) main objection to Agr is conceptual: it does not carry any intrinsic semantic properties. All Agr comes equipped with are $\phi$-features, which are Interpretable, hence irrelevant for the interpretive component. The sole purpose of Agr is to allow $\mathrm{V}$ to assign Case. It thus has a purely grammatical function, as opposed to any other lexical or functional head. By dropping the assumption of a unique checking relation per projection, it seems more economical to evoke an additional specifier of an independently needed head to check accusative. This head is $v$ whose "intrinsic" property is thematic. Movement of the object to an outer Spec of $v \mathrm{P}$ involves one projection less and does not run into trouble with the interpretation of Agr. Zwart presents data that challenge the central presupposition of this line of reasoning. He argues that some constructions involve a head that is responsible for nothing but accusative marking-just like Agr.

Consider a simple transitive sentence in Dutch. The object in (3) appears to the left of the sentential adverb. Depending on whether we adopt multiple functional projections (AgrP) or multiple specifiers (of $v \mathrm{P}$ ), we face the following two options (where I assume the Copy Theory of movement and indicate all relevant copies in the relevant derivations in boldface, here and in the following): ${ }^{8}$

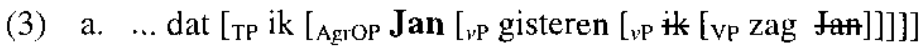

b. ... dat [Tp ik [vp Jan [vP gisteren [vp ik [vp zag

that I Jan yesterday saw

'...that I saw Jan yesterday.'

purely grammatical element that has no intrinsic, semantic (+Interpretable) propertics. 1 follow common assumptions in taking $\mathrm{V}$ to be a $\theta$-assignor (internal argument) and the element that marks Case (accusative) when combined with a functional head (namely, Agr rather than $v$ ); $v$ assigns the external $\theta$-role. (For expository reasons, I sometimes switch between "Agr" and "AgrO", wherever it is not critical to finer distinguish agreement.)

8 Note that this type of adverb is unlikely to appear as low as $\nu \mathrm{P}$. As we will see presently, a temporal adverb such as gisteren 'ycsterday' comes in handy, though, to tease apart different interpretations, forcing the one we will be interested in. For the purpose of jllustration, namely to argue against multi$\mathrm{Spec} v \mathrm{P}$, it does not hurt to adjoin gisteren 'yesterday' to $v \mathrm{P}$. Manner adverbs (such as duidelijk 'clearly', snel 'quickly'), which are more likely to be $v$ /VP-related, would do here, too, but lead to unwanted ambiguities. Pending a more articulate theory of adverbial positions and insertion into the derivation - in this or any other framework - might help settle the current argument also, but I leave this issue for the future and concentrate on minimal assumptions. 
Bearing the availability of these two structures in mind, let us see what happens in Exceptional Case-Marking (ECM) contexts, i.e. contexts which typically involve accusative case-marking of the embedded subject by the matrix predicate.

Perception verbs like see can take infinitival complements. Such configurations employ ECM, even in Dutch. It is clearly the matrix verb that assigns accusative case to the subject of the embedded clause. In (4), Jan can be replaced by hem 'him', but not by hij 'he'. Consider the following, where the embedded verb is italicized:

(4) ... dat ik Jan gisteren zag winnen.

that I Jan yesterday saw win

'...that yesterday I saw Jan win.'

The adverb indicates that the embedded subject raises into the matrix clause, somehow checking case with the matrix verb zag, while thematically relating to the embedded verb winnen. We can thus assign (4) the following structures, parallel to (3):

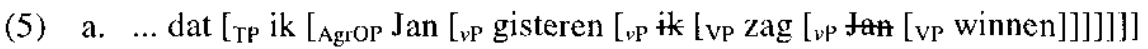

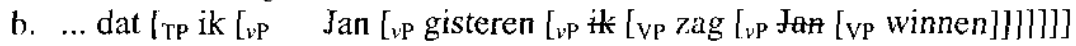

Recall that under a Spec-Head licensing configuration for Case checking, the matrix accusative case position is most likely the one where it is checked (unlike the INFL position of the embedded clause under some contortion of the government definition in earlier frameworks). We assume that the ECMed subject targets the matrix SpecAgrOP or SpecvP, respectively. ${ }^{9}$ So far either Case checking theory can handle the data. It gets more complicated if we add an additional argument to the embedded verb. This object also raises into the matrix clause, beyond the adverb (marked in boldface and italics):

(6) ... dat ik Jan de race gisteren zag winnen. that I Jan the race yesterday saw win

'...that yesterday I saw Jan win the race.'

Again, both hypotheses might deal with such cases, by simply adding (another) AgrOP or an additional $\nu \mathrm{P}-\mathrm{Spec}$ in the matrix clause. Take (7) to be the options for (6):

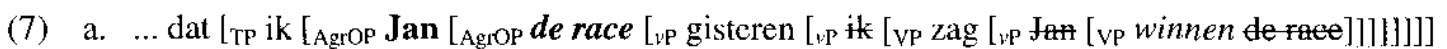

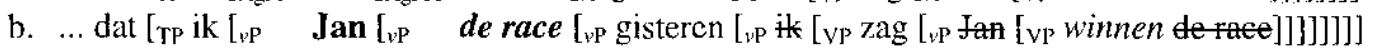

Examples like (4) or (6) show that movement into the matrix clause is allowed in ECM instances, and the fact that perception verbs like see are transitive suggests that they indeed have a $\nu \mathrm{P}$, possibly licensing accusative case (under the multi-Spec approach). If we want to hold on to (some form of) Burzio's Generalization ${ }^{10}$ - and to my knowledge, nobody in the "multi-Spec camp" has ever denied it-, we now expect that such movement is only allowed in the ECM-environment of transitive verbs; intransitive verbs

9 See Hornstein (1995), Boß̌ković (1986), Lasnik (1999) for relevant discussion of a minimalist approach to ECM.

${ }^{10}$ Burzio (1986) observed that (i) a verb which does not take an external argument does not assign accusative case and (ii) a verb that does not assign accusative case does not take an external argument. 
(unaccusatives) do not have $v \mathrm{P}$ (Chomsky 1995b: 315f.). Again, this is not an unusual assumption which I (or rather, Zwart) adopt; and to my knowledge, multi-Spec supporters have not yet proposed to allow for a $v \mathrm{P}$ with these verbs also.

If we could now find environments that involve $\phi$-checking (and Case assignment) of an embedded DP in a matrix clause whose verb does not project $\nu \mathrm{P}$, the multi-Spec approach would face a serious problem: it would look as if the matrix Case position is purely functional and does not involve intrinsic interpretive properties. Moreover, if this movement were the only strategy available, the problem would grow even bigger.

\subsection{Raising into an Uninterpretable Specifier?}

Let us consider movement into the matrix environment of a raising verb.

(8) ... dat Jan de race gisteren scheen te zullen winnen. that Jan the race yesterday seemed to will win

'...that yestcrday Jan seemed to be going to win the racc.'

Two remarks are in order. First, the addition of an auxiliary ensures that the adverb is construed with the matrix clause, the event of seeming, rather than the embedded clause. The adverb refers to a past event, while this auxiliary indicates a future event. This is indicated in the translation; it thus transpires that in English, too, the adverb must be construed with the matrix clause. Second, the Dutch equivalent of seem is also a raising verb, which can be shown with the same diagnostics as for English (it does not have an external argument, it cannot assign Case to an internal argument etc.). As such, it presumably lacks $v \mathrm{P}$ and should not be able to license Case.

Alas, it does: the object can be replaced with a pronoun, and this pronoun is marked accusative. ${ }^{11}$ It thus looks like the head that licenses case for the embedded object must bear a purely grammatical function-something AgrO used to do, but not $v$, which is independently motivated as a $\theta$-role assignor. However, $v$ is not otherwise motivated in (8). If Spec $v \mathrm{P}$ is involved, something else must be said. (9) indicates the dilemma '?':

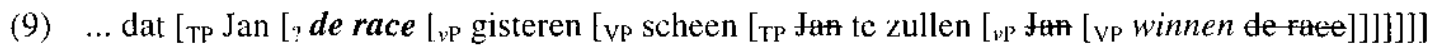

Traditional raising predicates are not the only contexts in which we find sentential complements of a "deficient" predicate of sorts, where by "deficient" I have a predicate in mind that does not necessarily make available a full-blown $v / \mathrm{VP}$-structure.

11 Actually, pronominalized de race 'the race' is neuter and does not show a Case distinction. However, if we replace the embedded predicate with something that takes a masculine (de man 'the man') or feminine (de vrouw 'the woman') argument, we get the distinction between hem 'him' or haar 'her' vs. *hij 'he' or *zij 'she'. Moreover, this cannot be the "default Case" in Dutch or some other quirk, as we then would expect nominative, as left dislocation constructions show (see Grohmann 2000: ch. 4). 


\subsection{Passivization}

We know that a passivized verb loses its property of assigning accusative case to its internal argument, the object; moreover, the external argument is at best optional and, if it shows up, it comes as a by-phrase. In other words, we could conjecture that passivized structures lack a $v \mathrm{P}$. Zwart does, so let us see what it could do for us. The Dutch passives work in the relevant respects just like their English counterparts. Consider (10):

(10) ... dat Jan het boek niet werd geacht te hebben gelezen.

that Jan the book not was considered.PART to have read.PART

'...that Jan was not considered to have read the book.'

First, the object of the matrix passivized verb is in the overt subject position, marked nominative; second, the embedded object has raised into the matrix clause where it gets accusative. The diagnostics are familiar: replacing the object by a pronoun shows this clearly (cf. fn. 11), it could not have moved to a position below (such as somewhere inside the embedded clause), and sentential negation indicates the matrix position, just as the adverb in the cases above, as the translation suggests. ${ }^{12}$

Not leaving out the disclaimer in fn. 12 completely, one could argue that this accusative position is purely grammatical, just as one might expect from Agr. Unless passive verbs really have a functional $v$ for thematic, or any other "intrinsic, interpretive" reasons, it is not clear how this position would be different from Agr.

\subsection{Transitive Expletive Constructions}

A third case to consider in this respect are Transitive Expletive Constructions in which the expletive is a grammatical place holder in subject position, not thematically selected; the matrix verb in (11) is a raising verb which neither takes an external argument nor projects a $v$, yet the matrix expletive, the lexical subject ('associate') selected by the embedded transitive verb, and its object all sit obligatorily in the matrix clause:

(11) ... dat er iemand het huis gisteren scheen te zullen kopen.

that there someone the house yesterday seemed to will buy

'...that someone seemed yesterday to be going to buy the house.'

\footnotetext{
${ }^{12}$ Arguably, matters are more complicated. Absence of $v P$ in passives would follow from Burzio's Generalization if passive verbs do not $\theta$-mark their subjects (Chomsky 1981): they do not bear an external $\theta$-role and do not assign accusative. But it does not need to. Baker, Johnson and Roberts's proposal (1989), for example, could be taken to mean that passive verbs actually do have $v \mathrm{P}$ to which the by-phrase is adjoined; $v$ absorbs the $\theta$-role of the verb (cf. also Roberts 1986). Presence of $v P$ would distinguish passive from middle verbs (but see Zwart 1986, 1998; see also Abraham 1995 for discussion of middles in German, Dutch and English). I cannot pursue the issue further (but see Tsimpli 1990 for treating Greek middles like passives, for cxample). Note, though, that if passive verbs have $\nu \mathrm{P}$, and SpecvP is not filled, one could envision a derivation proposed by Radford (1997), in which the complement of $\mathrm{V}$ moves to SpecTP via SpecvP. This would violate the Condition on Domain Exclusivity - a way to capture "anti-locality" effects of movement-, so I dismiss this alternative without further ado (see the framework sketched in Grohmann 2000 for details). Relevant for the present point is that it could be argued, and in fact has been, that passive structures lack the additional structure with the same intrinsic, interpretive properties regular transitive verbs have.
} 
The argument is clear: the embedded subject receives nominative in the matrix clause and the embedded object accusative, where the adverb is the standard diagnostic for position. The matrix verb does not have a $\nu \mathrm{P}$ where accusative could be checked, so the only possible analysis is that the object has moved to a separate functional projection responsible for accusative case checking (such as AgrOP).

\subsection{Some Concepts and Consequences}

The above discussion has shown that some verbs can assign accusative to the object of a complement clause, even if the Case-marking verb lacks a thematic $\nu \mathrm{P}$. What makes the predicates above (i.e. perception and raising verbs) interesting is that they are restructuring verbs. ${ }^{13}$ Without ascribing to a particular analysis of restructuring (see Wurmbrand 1998 for detailed discussion and references), it seems as if one property is Case-marking of an embedded verb in the matrix clause, and in the matrix clause only.

Zwart (forthcoming) formalizes this generalization roughly as follows: if a verb has an external argument, or if it is a restructuring verb and the verb in its complement domain has an external argument, it can license accusative case to an object in its functional domain. He takes it as a given that a verb without an external $\theta$-role also lacks $v \mathrm{P}$-it might be an elegant technical implementation, but it is not the only one.

One could suppose that in these cases $v$ is actually present (such as on the raising verb above), but this $v$ does not play any role other than marking accusative on the embedded object. This, in turn, could be empirically supported with Zwart's generalization. We could then propose that accusative case is always marked in SpecvP and if $v$ does not bear a $\theta$-function, the restructuring default kicks in.

This would be an unfortunate move, however. Chomsky (1995a) wants to get rid of Agr for one main reason: Agr only bears $\phi$-features, these are -Interpretable and will be deleted after checking, hence Agr should be invisible at LF. Rather than dealing with invisible entities at the interpretive interface, accusative could be checked by an element with intrinsic interpretable features, such as $v$. If, however, some structures have a $v$ which lacks such thematic properties, it would have the same purely grammatical function as Agr, be by definition invisible at LF, and face the same conceptual problem.

Zwart provides three arguments against assuming $v \mathrm{P}$ in the contexts above. The first one is similar to the point just made. At least with raising verbs, $v$ is not semantically motivated, so merging unmotivated $v$ with VP would be an instance of a global operation, a 'look ahead' mechanism, to license some relation further along the road.

The second argument concerns the specific circumstances. Consider (12):

(12) ... dat Jan niet scheen te sterven/worden gearresteerd/dansen that Jan not seemed to die/be arrested/dance

'...that Jan did not seem to die/be arrested/dance.'

${ }^{13}$ Apart from raising and ECM-verbs, Dutch has two more restructuring verb classes, causatives and some control verbs. These are irrelevant for the present discussion, however, as both assign an external $\theta$-role (and are thus on a par with ECM-verbs). 
According to Zwart's generalization, the matrix accusative position should only be active in the context of a transitive embedded verb. If the embedded verb is intransitive, it should be inactive. (12) shows that the generalization is not ad hoc but empirically grounded: the subject of an unaccusative, passive or unergative verb raises to the matrix subject position (and receives nominative) - it does not raise to the object position to get accusative. If the latter were to be identified as the outer Spec of $\nu \mathrm{P}$, something else needs to be said why it cannot be an appropriate licensing position in these contexts.

Lastly, the entire restructuring complex is subject to Burzio's Generalization. In (13a), the embedded object moves into the matrix object (accusative) position; in (13b), it moves into the matrix subject (nominative) position:

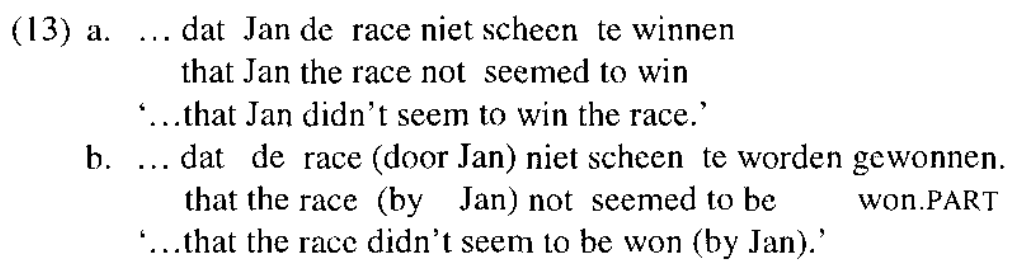

The difference between the two sentences is that the embedded verb of (13b) is passivized, hence does not assign an external $\theta$-role, and by Burzio's Generalization, no accusative should be assigned. This suggests further that it is transitivity of the embedded predicate that is relevant in restructuring contexts, which could then be captured, if the potential for licensing accusative comes from the embedded $v$, with $v$ being responsible for projecting Agr (which in restructuring contexts takes place in the matrix clause).

In sum, we now have an empirical reason to doubt the conceptual condemnation of Agr: it does not really seem to be the case that the (accusative) Case-assignor always has intrinsic +Interpretable features. The constructions above indicate that were $v$ able to mark accusative on its specifier, it would do so without any interpretable properties in some circumstances. These circumstances involve restructuring contexts. Thus, there is no conceptual reason anymore to dismiss Agr as a possible functional head that only plays a grammatical role. This does not imply that Agr is a better choice as accusativemarker than $v$, but it levels the difference. Furthermore, there might be empirical pay-off of an Agr-based Case-marking (and $\phi$-checking) framework.

The argument Chomsky raises against Agr is even more puzzling in the context that Chametzky (2000: 149) notes: "In the tradition as represented by Speas [(1990)] and Abney [(1987)], the semantic interpretability of [f]unctional [c]ategories is always understood to be dependent on some [l]exical [c]ategory or other: it is 'parasitic' or 'second-order'.",

\footnotetext{
14 Anna Roussou (p.c.) points out that there is a straightforward line of reasoning to consider Agr endowed with +Interpretable features. In particular, if our proposal regarding argument movement in terms of $\phi$-feature (rather than Case) checking is on the right track (Grohmann 2000; ch. 2 and references cited; see also Roberts and Roussou 1999), we would expect Agr to play an active role in the realization of $\phi$-properties. We could push this a little bit further and think of Agr as the PF-licenser for arguments: in case its specifier is a DP, that spells out as the full nominal; in other instances, it might spell out as a clitic. In Grohmann (2000), I briclly consider such a view of clitics at the cnd of chapter 4 (see also in, 20 of chapter 2).
} 
Next we will see another proclaimed instance of "invisibility for interpretation," namely of intermediate projection levels. The arguments for that have recently been dropped; maybe Agr can be resurrected from fallen grace on the same grounds.

\section{Phrase Structure and Natural Relations: Specifiers vs. Adjuncts}

Alongside the claim that phrases may not have more than one specifier, I also want to push the idea that adjunction, though theoretically unlimited in number, is restricted to base-generation; that is to say, movement qua Copy plus Merge cannot adjoin a phrase YP to some projection XP, it can only be merged to X' and form SpecXP.

\subsection{X'-Structure and "Invisibility"}

Recall the structural relations I suggest, extended from $(2):^{15}$

(14)

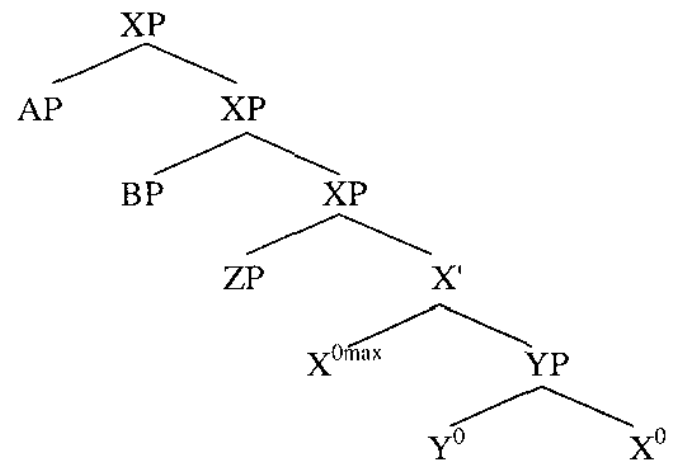

$\mathrm{YP}$ is the complement of $\mathrm{X}\left(\mathrm{X}^{0 \mathrm{max}}\right)$ and $\mathrm{ZP}$ its unique specifier; $\mathrm{Y}\left(\mathrm{Y}^{0}\right)$ has adjoined to $\mathrm{X}$, and $\mathrm{AP}$ and $\mathrm{BP}$ are adjoined to (or are, in the sense used throughout, adjuncts of) XP. Structural relations must be defined as to allow $\mathrm{Y}, \mathrm{YP}$ and $\mathrm{ZP}$ to enter into a checking relation with $\mathrm{X}$, and only these. Likewise, we need to derive that $\mathrm{AP}$ and $\mathrm{BP}$ can only be base-generated in the positions indicated, that is, all adjuncts must be the result of Direct Merge only; if they could be derived, we would expect them to enter into a checking relation with the head (movement being driven by Greed); see chapter 4 of Grohmann (2000) for empirical support. This expectation just does not seem to fit with current assumptions. Moreover, we cannot uphold this expectation if the sketch of $\mathrm{X}^{\prime}$-relations I present here is on the right track. These are the desiderata. Let us go and derive them.

In the original formulation of Bare Phrase Structure (Chomsky 1994, 1995a), the relevant projection (intermediate, not fully projected $\mathrm{X}^{\prime}$ or, as used here, $\mathrm{XP}$ ) was different from the element originally merged to $\left(\mathrm{X}^{0}\right)$ and the final projected phrase (XP

${ }^{15}$ By convention, I label the first projection of a head $X X^{\prime}$ and any subsequent, recursive levels of projection $X P$. While it might be confusing in light of the better known "X-bar recursion," I believe it is a more appropriate notation in the current context. I hope it does not confuse the reader too much. 
or $\mathrm{X}^{\max }$ ) only in being neither minimal nor maximal. As such it was stipulated to be invisible to interpretation, as only $\mathrm{X}^{\mathrm{min}}$ (the terminal element) and $\mathrm{X}^{\text {max }}$ (the fully projected phrase) are interpretable objects-apparently following from bare output conditions; see Chomsky (1995b: 242f.). Building on Muysken (1982), minimal and maximal projections are identified by relational properties of categories only (i.e. Spec, Comp and Adj, depending on the relation between these elements and the Head or its projections; see also Freidin 1992). These relations, and only these, basically yield (2) or (14)—without, though, giving the $X^{\prime}$ any interpretive status. This allowed the original minimalist framework (and its extensions in Chomsky 1998, 1999) to rule in multi-Specs. ${ }^{16}$ It distinguished between adjunction (of heads or adjuncts) and substitution (specifiers) in that the former creates a two-segment category, whereas the latter forms a new category.

Consider first the proclaimed "invisibility" of intermediate, not fully projected elements, here taken to be a unique $X^{\prime}$ and all XPs dominated by the highest, fully projected XP. If we could remove the stipulation that these elements are invisible, we could easily enforce unique specifiers by stipulating, in turn, that a specifier must merge with $X^{\prime}$, and that there is only one $X^{\prime}$ per projection. I will try to do more than stipulate, but if all else fails, this position might not be the most unreasonable one to hold.

There are two arguments for $\mathrm{X}^{\prime}$ invisibility, one conceptual and one empirical. The conceptual argument is that $X^{\prime}$ is not interpreted at LF. In support, Chomsky (1995b: 382, note 24) cites the works of Fukui (1986), Speas (1986), Oishi (1990), and Freidin (1992). He also tries to justify the oddness of an element being "present but invisible" (op. cit.) from a derivational perspective (acknowledging Sam Epstein) by virtue of these nodes being "fossils" (Chomsky's quotation marks). By this he means that they were visible at some point, namely prior to the operation that turned them invisible. The empirical argument is a partial recreation of the LCA of Kayne (1994), without the need to adopt other ingredients of Kayne's program (which are basically incompatible with Checking Theory).

In a recent paper, Chomsky (1999: 32) notes that "[t]he conceptual and empirical arguments for X' [here, XP] invisibility are slight". The lack of LF-interpretation of X', or our XP-level, he continues, "is questionable and in fact rejected in standard approaches." Regarding a minimalist implementation of the LCA, he remarks that "that result, if desired, could just as well be achieved by defining 'asymmetric c-command' to exclude (X', YP)," adding "a stipulation, but not more so than $\mathrm{X}^{\prime}$ invisibility."

We could then simply stipulate that the first projection of a head is $X$ ', subsequent projections are XP, and only $X^{\prime}$ accepts a specifier. But let us try to derive these results, or at least motivate them with coherent assumptions and conditions, much in line with the minimalist spirit of Bare Phrase Structure.

\subsection{X'-Structure and Natural Relations}

It is my understanding that standard Bare Phrase Structure (Chomsky 1994, following Muysken 1982), and virtually all its applications, assume $X^{\prime}$ to be invisible for inter-

16 This conclusion might be wrong, at least the way I put it. As Chomsky (1999: 39, note 66) puts it, "[i]t is sometimes supposed that [multi-Spec] is a stipulation, but that is to mistake history for logic." 
pretation, hence not relevant for expressing structural relations--despite Chomsky's (1999) nonchalant remarks. The reason I am pounding on the latter is the following. If phrase structure should be expressed in terms of "relational properties of categories, not properties inherent to them" (Chomsky 1995b: 242), recourse to invisibility of some objects in the phrase marker need not be an issue at all-especially not, if labels do not exist in the first place (Collins 1999). We can define these objects, and as such the structure of a projection, with natural relations. As it happens, Chomsky suggests something very similar himself, and I am going to explore these relations.

As one of the conditions of "good design" of language ${ }^{17}$ Chomsky (1998: 27) lists "[r]elations that enter into $\mathrm{C}_{\mathrm{HL}}$ either (i) are imposed by legibility conditions, or (ii) fall out in some natural way from the computational process." Regarding (ii), he suggests that Merge yields two relations for free, Sister and Immediately Contain (p. 31, also Chomsky 1999).$^{18}$ Let us assume, maybe not innocently, that this is so. If these two relations come for free, they are arguably the most natural relations to express phrase structure (under the guidance of Muysken's suggestion). Chomsky suggests that by merging the objects $\alpha$ and $\beta$, forming the new object $\mathrm{K}(\alpha, \beta)$, we can understand Sister to hold of $(\alpha, \beta)$ and Immediately Contain of $(K, \alpha),(K, \beta)$ and $(K, K)$, if Immediately Contain is reflexive.

If Sister and Immediately Contain are the most natural relations-most natural because they are the only direct relational result of merging two objects and as such come for free (as I interpret Chomsky)-, it might be natural to assume that they play an elementary role in defining certain relations. One such relation is structural, among the objects of a given phrase. Another relation to be addressed is operational, say, to establish relevant checking configurations. Suppose this is indeed so, and suppose that one way of extending these most natural relations is by applying "the elementary operation of composition of relations," as Chomsky (1998: 31) does. Such an application, "in all possible ways" (op. cit.), yields the new relations (15i) and (15ii). There is also a third relation-however not the one Chomsky suggests. I call this relation Extended Sister: ${ }^{19}$

(15) i. Contain: transitive closure of (immediate-contain)

ii. Identity: (sister(sister))

iii. Extended Sister: (sister(immediately-contain))

If we take Sister and Immediate Contain to be primitives, and the first application of composition to be the next "most natural" relations-regardless of why this is or should be so (see Uriagereka 1999)-, we should try and explore how far we can push these five relations to define the most local configurations in $\mathrm{C}_{\mathrm{HL}}$. The area I want to concentrate on is an appropriate checking configuration in these terms.

${ }^{17}$ One aspect of such conditions is the above mentioned guiding principle, formulated as "less machinery is better than more" by Chomsky (1998: 27, fn. 61).

${ }^{18}$ Note that this is already a non-trivial premise, which I am nevertheless willing to accept. One might pursue another route, replacing sisterhood (and related dominance) relations with a primitive notion of c-command. See e.g. Frank, Hagstrom and Vijay-Shankar (1999), Frank (forthcoming) for exposition.

19 That (15iii) should be the third relation was also pointed out by Uriagereka (1999). Chomsky's original "third relation" was c-command, hence more or less trivially derived: (sister(contain)). This is not the case, however, as Contain itself is not a primitive but a derived relation. As Uriagereka points out, Chomsky's third relation does not have the strictly local character Extended Sister has. The next subsection deals with the possible relevance of this state of affairs to our discussion. 


\subsection{X'-Structure and Checking Configurations}

Features are arguably checked in very local relationships, and all evidence so far suggests that we want to include Head-Comp, Head-Head and Spec-Head configurations to be admissible, but no other (Chomsky 1995a). Chomsky (1993) defines a checking domain which derives the desired results. ${ }^{20}$ However, it also allows more than one specifier to be within the checking domain of a relevant head as well as adjuncts (which would simply not check a feature by stipulation). In the framework I propose neither one is desired, not even acceptable. So let us consider a way of replacing Chomsky's checking domain with an alternative way of capturing the checking configurations endorsed here in purely relational terms (analogous to the checking domain).

Given the natural relations discussed above, we could define feature checking with a Checking Condition along the following lines:

(16) Checking Condition

A head $\mathrm{H}$ endowed with feature $\mathrm{F}$ can enter into a checking relation with an object $\mathrm{O}$ in the phrase marker with matching $\mathrm{F}$ under a Natural Relation.

(17) Natural Relation

Let a Natural Relation be

i. any of the primitive relations provided by Merge and

ii. any relation resulting from the first-order composition of primitive relations.

We are thus dealing with five Natural Relations: ${ }^{21}$ Sister, Immediately Contain, Contain, Identity, and Extended Sister. Returning to (14), here in yet another modified form to be as explicit as possible, we can now ensure that the three desired configurations, and only those (for better or worse), are permissible checking configurations:

(18)

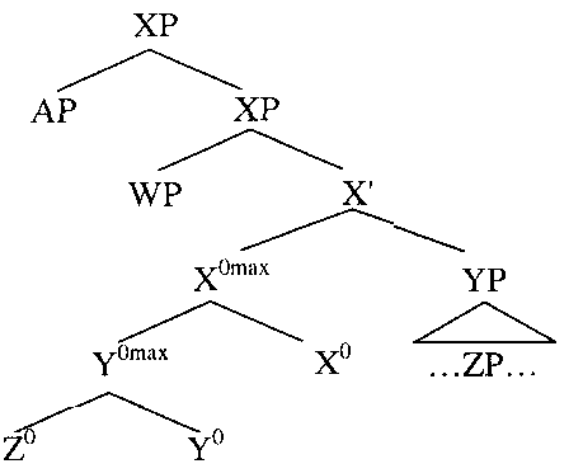

${ }^{20}$ The checking domain is defined as an "elsewhere' set" (Chomsky 1993: 12): it is the minimal residue of a domain of a head. The "domain" is evaluated over "the set of nodes contained in [the least fullcategory maximal projection] dominating the [head]" (p. 11), and the "minimal residue" is a "minimal subset" of the domain minus the "complement domain." In essence, this allows a head to enter a checking relation with anything adjoined to it, with its complement, with its specifier(s)-formally not different from adjuncts-, and also with the highest XP adjoined to specifiers (or adjuncts). We will modify these relations somewhat.

${ }^{21}$ Capitalization of natural relations identifies this as a technical term in the sense outlined above-and subject to the usual disclaimer: if these are primitives, why so, why only these, why only the first-order composition of relations and so on. For the sake of discussion, let us assume that the first-order application of composition is the most basic one. 
According to (16) $\mathrm{X}, \mathrm{Y}$ and $\mathrm{Z}$ are heads which bear features that require checking, under the familiar umbrella of Full Interpretation, Greed and Economy, i.e. if no features are checked, movement should not occur. YP is in CompXP and hence must enter a checking relation with X, if Merge is costly. WP is in SpecXP and must also enter into a checking relation with $\mathrm{X}$, for either one of the above reasons. (ZP is irrelevant for our discussion.) If AP is a specifier, it too must check on $X$; if it is an adjunct (as assumed here), it need not, for reasons we get back to momentarily. Let us run through the desired and undesired checking relations and the predictions of applying the Checking Condition.

The most straightforward is presumably Head-Comp, as the Natural Relation Sister is an immediate fall-out from the application Merge. Given that X and YP above should enter into a checking relation, if we take (at least one understanding of) "selection" to be expressed this way, and that $\mathrm{X}$ is Sister to YP, this is the first desired result: Head-Comp checking is licensed by Sister.

Once $\mathrm{X}$ and $\mathrm{YP}$ are licensed, we can move (the complex head) $\mathrm{Y}$ to $\mathrm{X}$, an instance of head-to-head adjunction. There are two possibilities: $\mathrm{Y}^{(1) \max }$ and $\mathrm{X}^{0}$ enter into a checking relation (Sister) or $\mathrm{Y}^{0 \max }$ and $\mathrm{X}^{0 \mathrm{max}}$ do (Immediate Contain). Assume the latter, for reasons I address shortly. So Head-Head checking is licensed by Immediate Contain.

Merging WP with $X^{\prime}$, the label of the object $\left(X^{0 \max }, Y P\right)$, should ideally result in licit Spec-Head licensing. It does: WP is Sister to $X^{\prime}$ which, in turn, Immediately Contains $X^{0 \max }$, and $X^{0 \max }$ is the Extended Sister of WP, one of the three results of the composition of our two primitive relations. Spec-Head checking is now legitimized by Extended Sister.

If we then merge $\mathrm{AP}$ and $\mathrm{XP}$ - which is the label of (WP, $\mathrm{X}^{\prime}$ ), or more precisely, $\mathrm{XP}$ is the ordered set $\{(\mathrm{X},(\mathrm{WP},(\mathrm{X},(\mathrm{X}, \mathrm{YP})))\}$, regardless of the label of the intermediate level of projection-, we should be able to find a Natural Relation between AP and $\mathrm{X}$ if the two are to enter into a checking relation. Alas, we do not find such a relation. The composition (sister(AP)) returns XP, (immediate-contain(AP)) gives nothing relevant (AP's internal structure), (contain(AP)) is equally uninteresting, (identity(AP) yields AP, and (extended-sister(AP)) churns out $X^{\prime}$, not a head. We thus take AP to be unable to check a feature-at least not with the head of the projection.

In other words, licensing of AP is of a different nature than licensing of WP. If WP is indeed a specifier, we recreate the Spec-Head configuration and exclude multiple specifiers trivially: no element merged to any position above (WP, $\mathrm{X}^{\prime}$ ) can enter into a Natural Relation with $\mathrm{X}$ and hence cannot check off a feature with $\mathrm{X}$. It follows that AP is an adjunct, and that adjuncts do not enter checking configurations with heads.

The one non-obvious step above concerns Head-Head configurations. I suggested that Immediate Contain is the relevant configuration. Let us see how and why.

First, consider $\mathrm{Y}$ and $\mathrm{X}$ above. If the relationship were Sister, rather than Immediate Contain, we would expect that $Z$ and $Y$ are also licensed by Sister. Looking at the structure above, however, we see that $Z^{0}$ is in Sister relation with $Y^{(0}$, whereas $Y^{(0) \max }$ is Sister to $X^{0}$. We could imagine that $Y^{0}$ and $Y^{0 \max }$ have identical features, perhaps even duplicate, or that in $\left[Z^{0}-Y^{0}\right]-Y^{(0 m a x}$ the feature checked between $Z^{0}$ and $Y^{0}$ is activated on $\mathrm{Y}^{\mathrm{Omax}}$ by some other mechanism, thus removing the need to multiply features. Neither option is impossible, and I opt for the latter, calling the mechanism "mediation." 
The conceptual advantage of Immediate Contain as the relevant relation is that concerns the part of the two-segment head that projects, which could thus be conceived of as being more "active" in the derivational process. This then allows a higher segment of a complex head to enter into a checking relation with anything outside that head. A simple head may check a feature with its Spec as described above. But what if WP needs to be in a checking configuration with $\mathrm{Y}^{0}$ ? In this case, $\mathrm{X}^{0 \max }$ acts as the intermediary, by virtue of Containing $\mathrm{Y}^{0}$. As we do not want to stack Natural Relations, I suggest that the relevant property of $\mathrm{Y}^{0}$ can be mediated to $\mathrm{X}^{0 \max }$ and as such be marked on WP.

The obvious case in hand is, of course, Case-marking. Suppose $\mathrm{X}=\mathrm{Agr}, \mathrm{Y}=v$, and $Z=V$, with WP $=$ DP. X checks $\phi$-features on WP (Extended Sister). Apart from headinternal licensing, $Z$ can mark Case on WP via the intermediary $X$ (Contain). Convoluted this may sound, it buys us another earlier assumption: Case-marking is not formal feature checking per se, but rather a reflex of a local configuration.

This subtle difference can now be expressed more formally.

(19) Feature Mediation

In a structure $\left[\alpha_{\mathrm{n}}\left[\alpha_{\mathrm{m}} \alpha_{1}-\alpha_{m}\right]-\alpha_{n}\right]$, where $\alpha$ is a head and $\alpha_{n}$ Contains all $\alpha$, $\alpha_{1}, \alpha_{2} \ldots \alpha_{m-1}, \alpha_{m}$ mediate a feature $\mathrm{F}$ to $\alpha_{n}$, and $\alpha_{\mathrm{n}}$ becomes intermediary to mark $F$ as a reflex of a licensed checking configuration.

Feature mediation could thus be viewed as an escape hatch for the one-feature-perprojection checking restriction. This makes potentially a number of predictions, in particular that this strategy should not be on a par with feature-checking, i.e. it should not be thought of as an alternative checking operation (Occam's Razor). Case-marking conceived as a reflex of a feature is one such instance. ${ }^{22}$ (I present more potential cases in chapter 5 of Grohmann 2000.)

We can summarize the relevant relations and arising checking configurations:

(20) Checking Configurations

i. Head-Comp: Sister

ii. Head-Head: Immediate Contain

iii. Spec-Head: Extended Sister

iv. F-mediation: Contain

v. XP-adjunction: Identity

We went through all relations except for $(20 \mathrm{v})$. As suggested, licensing of adjuncts if different from specifiers, and one way to express this difference is to deny them an appropriate checking configuration. On the other hand, as not every adjunct can just adjoin anywhere without restrictions, we want some control operation. This could be checking on itself. By Identity, then, an adjunct checks a feature on itself. ${ }^{23}$

22 As can be tested trivially, Feature mediation can only ever have an effect on a complex head and its specifier, i.e. specifiers are the only elements that can be marked qua reflex.

23. Norbert Hornstein (p.c.) reports Jairo Nunes to have suggested that an adjunct checks a feature on itself. I cannot delve into any deeper discussion. The point is whether we want adjunction to be licensed in terms of checking or not (cf. Ernst, to appear), Identity, as a Natural Relation, might be expected to do something, and this could be one option. Again, this is not a necessary conclusion to draw, but a possible consequence. 
As for the undesired configurations, we can ignore the fact that $\mathrm{X}^{\prime}$ Immediately Contains X or that XP Contains X, as both are projections of X and checking is not needed. Likewise, we can glance over the fact that XP Immediately Contains WP, as neither is a head and as such does not need check features either. As far as I can see, we can ignore all other hypothetical relations also, on the same grounds.

It might be the case that this modification of the original discussion of Chomsky (1994, viz. 1995b: 241-249) does not amount to much more than fancy words expressing that "a specifier is the object merged with $\mathrm{X}$ ' which immediately dominates $\mathrm{X}$, an adjunct is an object merged with an intermediate projection of $\mathrm{X}$ which does not immediately dominate X." If $\mathrm{X}^{\prime}$ (or XP) is not invisible, this might be the most straightforward way to implement our desiderata. I hope to have given my stipulations and assumptions, replacing some standard relational notions, a little bit of validity, enough to keep us going.

\section{4 $\quad \mathrm{X}^{\prime}$-Structure and Licensing Conditions}

The core property of distinction between specifiers and adjuncts in traditional terms is that the latter are purely optional: nothing hinges on insertion of an adjunct--if it is not part of the LA, it does not show up, yet the derivation will converge, all other things being equal. But if the object fails to raise to check $\phi$-features and receive Case, or if the Wh-element in English does not undergo movement to check off [Wh], the derivation crashes. On the other hand, not all adjuncts are licensed equally well in all positions. This has cast some doubt on the above reasoning (see Cinque 1999 for a radical implementation of obligatory adverbial positions, or Alexiadou 1997, Laenzlinger 1998). However, if adjuncts and specifiers are formally different, such as along the lines sketched above, we could imagine that the licensing conditions of both are different, too.

If we take obligatoriness to be reflected in the syntax, we might want to tie it to feature checking. All displacement takes place to check features in the appropriate licensing configuration, and by definition, a head is involved. As we have seen above, adjuncts are not in a relation to heads that would permit exchange of feature values. But it is not unreasonable to assume that they need to be licensed somehow, and in that case we would still want to express this syntactically. I thus take either suggestion from above as a viable option, either in terms of Identity, where adjuncts check a feature on themselves.

A number of licensing conditions have been evoked over the years, and even if we assume that the licensing is not in a Spec-Head agreement (pace Kayne 1994, Cinque 1999), we still have a wide range of proposals to consider, and I will leave the discussion at that. See, for example, Jackendoff (1972), Ernst (1984) and relevant references cited for early proposals, and Laenzlinger (1998), Svenonius (2000) for more recent versions. Ernst (to appear) appeals to Full Interpretation as relieving adjuncts from the necessity of entering any checking relation. If this goes through, Identity can simply be considered the saturation relation for Full Interpretation, no formal checking is required. 


\section{Final Remarks}

In sum, we have seen empirical evidence against multiple specifiers, and we have considered a technical implementation to rule them out on principled grounds. If not successful (that is, if they cannot be derived one way or another), I can at least make the following stipulations, which are roughly equivalent to additional assumptions standard Bare Phrase Structure must make:

(21) Specifiers and adjuncts are formally different objects in the phrase marker

i. adjunction to XP must be the result of base-generation (Direct Merge)

ii. specifiers are base-generated or result from Move (Copy plus Merge)

iii. specifiers enter a checking relation with a head and must be unique

iv. adjunction cannot check features with a head and need not be unique

\section{References}

Abney, Stephen (1987): The English Noun Phrase in Its Sentential Aspect. Doctoral dissertation, Massachusetts Institute of Technology, Cambridge

Abraham, Werner (1995): Deutsche Syntax im Sprachenvergleich. Grundlegung einer typologischen Syntax des Deutschen. Tübingen: Gunter Narr

Alexiadou, Artemis (1997): Adverb Placement. A Case Study in Antisymmetric Syntax. Amsterdam: John Benjamins

Baker, Mark; Johnson, Kyle; Roberts, Ian (1989): Passive Arguments Raised. Linguistic Inquiry 20. 219251

Bobaljik, Jonathan David; Jonas, Dianne (1996): Subject Positions and the Roles of TP. Linguistic Inquiry 27. 195-236

Boeckx, Cedric (2000): EPP Eliminated. Manuscript, University of Connecticut, Storrs

Bošković, Željko (1986): The Syntax of Non-Finite Complementation. An Economy Approach. Cambridge, MA: MIT Press

Bošković, Željko (1999): On Multiple Feature Checking: Multiple Wh-Fronting and Multiple Head Movement. In: Epstein, Samuel David; Hornstein, Norbert (eds.): Working Minimalism. Cambridge, MA: MIT Press. 159-187

Burzio, Luigi (1986): Italian Syntax. Dordrecht: Reidel

Castillo, Juan Carlos; Drury, John; Grohmann, Kleanthes K. (1997): Cyclic Evaluation as a Way to Achieve Local Economy. Manuscript, University of Maryland

Castillo, Juan Carlos; Drury, John; Grohmann, Kleanthes K. (1999): Merge Over Move and the Extended Projection Principle. In: Aoshima, Sachiko; Drury, John; Neuvonen, Tuomo (eds.): University of Maryland Working Papers in Linguistics 8. 63-103

Chametzky, Robert (2000): Phrase Structure. From GB to Minimalism. Oxford: Blackwell

Chomsky, Noam (1981): Lectures on Government and Binding. Dordrecht: Foris

Chomsky, Noam (1982): Some Concepts and Consequences of the Theory of Government and Binding. Cambridge, MA: MIT Press

Chomsky, Noam (1986): Barriers. Cambridgc, MA: MIT Press

Chomsky, Noam (1993): A Minimalist Program for Linguistic Theory. In: Hale, Kenneth; Kcyser, Samuel Jay (cds.): The View from Building 20. Essays in Honor of Sylvain Bromberger. Cambridge, MA: MIT Press, I-52. Reprinted in Chomsky (1995b). 167-217

Chomsky, Noam (1994): Bare Phrase Structure. MIT Occasional Papers in Linguistics 5. Cambridge, MA: MITWPL. Reprinted in: Webelhuth, Gert (ed.) (1995): Government and Binding Theory and the Minimalist Program. Oxford: Blackwell. 383-439 
Chomsky, Noam (1995a): Categories and Transformations. Manuscript, Massachusetts Institute of Technology. Appeared in Chomsky (1995b). 219-394

Chomsky, Noam (1995b): The Minimalist Program. Cambridge, Mass.: MIT Press

Chomsky, Noam (1998): Minimalist Inquiries: The Framework. MIT Occasional Papers in Linguistics 15. Cambridge, MA: MITWPL. Reprinted in: Martin, Roger; Michaels, David; Uriagereka, Juan (eds.): Step by Step. Cambridge, MA: MIT Press. 89-155

Chomsky, Noam (1999): Derivation by Phase. MIT Occasional Papers in Linguistics 18. Cambridge, MA: MITWPL

Cinque, Guglielmo (1999): Adverbs and the Universal Hierarchy of Functional Projections. Oxford: Oxford University Press

Collins, Chris (1999): Eliminating Labels. Manuscript, Cornell University, Ithaca

den Dikken, Marcel (1995): Binding, Expletives and Levels. Linguistic Inquiry 26, 347-354

Doron, Edit, Heycock, Caroline (1999): Filling and Licensing Multiple Specificrs. In: Adger, David; Pintzuk,Susan; Plunkett, Bernadette; Tsoulas, George (eds.): Specifiers: Minimalist Approaches. Oxford: Oxford University Press. 69-89

Epstein, Samuel David; Seely, T. Daniel (1999): SPEC-ifying the GF "Subject;" Eliminating A-Chains and the EPP within a Derivational Model. Manuscript, University of Michigan, Ann Arbor and Eastern Michigan University, Ypsilante

Ernst, Thomas (1984): Towards an Integrated Theory of Adverb Positions in English. Bloomington, IN: Indiana University Linguistics Club

Ernst, Thomas (1998): The Scopal Basis of Adverb Licensing. In: Tamanji, Pius N.; Kusumoto, Kiyomi (eds.): Proceedings of the 28th Meeting of the North East Linguistic Society. Amherst, MA: GLSA, University of Massachusetts. 127-142

Ernst, Thomas (to appear): The Syntax of Adjuncts. Cambridgc: Cambridge University Press

Frank, Robert (forthcoming): Phrase Structure Composition and Syntactic Dependencies. Cambridge, MA: MIT Press

Frank, Robert; Hagstrom, Paul; Vijay-Shanker, K. (1999): Roots, Constituents and C-Command. Paper presented at GLOW 22, Zentrum für allgemeine Sprachwissen-chaft, Typologic und Universalienforschung, Berlin, Germany. [March 29-31]

Freidin, Robert (1992): Foundations of Generative Grammar. Cambridge, MA: MIT Press

Fukui, Naoki (1986): A Theory of Category Projection and Its Applications. Doctoral dissertation, Massachusetts Institute of Technology, Cambridge

Grohmann, Kleanthes K (2000): Prolific Peripheries: A Radical View from the Left. Doctoral dissertation, University of Maryland, College Park. [http:/www.punksinscience.org/kleanthes/diss.html]

Grohmann, Kleanthes K.; Drury, John; Castillo, Juan Carlos (2000): No More EPP. In: Billerey, Roger; Lillchaugen, Brook (eds.): Proceedings of the Nineteenth West Coast Conference on Formal Linguistics. Somerville, MA: Cascadilla Press. 153-166

Hornstein, Norbert (1995): Logical Form. From GB to Minimalism. Oxford: Blackwell

Jackendoff, Ray (1972): Semantic Interpretation in Generative Grammar. Cambridge, MA: MIT Press

Jackendoff, Ray (1977): X-bar Syntax: A Study of Phrase Structure. Cambridge, MA: MIT Press

Kayne, Richard S. (1994): The Antisymmetry of Syntax. Cambridge, MA: MIT Press

Koizumi, Masatoshi (1994): Laycred Specifiers. In: Gonzàlez, Mercè (ed.): Proceedings of the 24th Meeting of the North East Linguistic Society, Vol. 1. Amherst, MA: GLSA, University of Massachusetts. 255-269

Koopman, Hilda; Sportiche, Dominique (1991): The Position of Subjects. Lingua 85. 211-258

Kuroda, Sige-Yuki (1988): Whether We Agree or Not: A Comparative Syntax of English and Japanese. Lingvisticae Investigationes 12. 1-47

Laenzlinger, Christopher (1998): Comparative Studies in Word Order Variation: Adverbs, Pronouns and Clause Structure in Romance and Germanic. Amsterdam: John Benjamins

Lasnik, Howard (1999): Minimalist Analysis. Oxford: Blackwell

Lasnik, Howard (to appear): A Note on the EPP. Linguistic Inquiry

Lasnik, Howard; Saito, Mamoru (1992): Move $\alpha$ Conditions on Its Applications and Outputs. Cambridge, MA: MIT Press

Moro, Andrea (1989): There/Ci as Raised Predicates. Manuscript, Massachusetts Institute of Technology, Cambridge

Moro, Andrea (1997): The Raising of Predicates. Cambridge: Cambridge University Press 
Mulders, Iris (1996): Multiple Checking and Mirrored Specifiers: The Structure of CP. Manuscript, Utrecht University

Muysken, Pieter (1982): Parametrizing the Notionn "Head." Journal of Linguistic Research 2, 57-75

Nunes, Jairo (1995): The Copy Theory of Movement and Linearization of Chains in Minimalist Program. Doctoral dissertation, University of Maryland, College Park

Nunes, Jairo; Thompson, Ellen (1998): Appendix. In: Uriagereka, Juan (cd.): Rhyme and Reason: An Introduction to Minimalist Syntax. Cambridge, MA: MIT Press 497-521

Oishi, Masayuki (1990): Conceptual Problems of Upward X-bar Theory. Manuscript, Tohoku Gakuin University

Pesetsky, David (2000): Movement and Its Kin. Cambridge, MA: MIT Press

Radford, Andrew (1997): Syntactic Theory and the Structure of English. A Minimalist Approach. Cambridge: Cambridge University Press

Richards, Norvin (1997): What Moves Where When in Which Language? Doctoral dissertation, Massachusetts Institute of Technology, Cambridge

Richards, Norvin (1999): Featural Cyclicity and the Ordering of Multiple Specifiers. In: Epstein, Samuel D.; Hornstein, Norbert (eds.): Working Minimalism. Cambridge, MA: MIT Press. 127-158

Roberts, Ian (1986): The Representation of Implicit and Dethematized Subjects. Dordrecht: Foris

Roberts, Ian; Roussou, Anna (1999): Interface Interpretation. Manuscript, Universität Stuttgart and University of Cyprus, Nikosia

Speas, Margaret (1986): Adjunction and Projection in Syntax. Doctoral dissertation, Massachusetts Institute of Technology, Cambridge

Speas, Margaret (1990): Generalized Transformations and the D-Structure Position of Adjuncts. Manuscript, University of Massachusetts, Amherst

Stowell, T. (1981): Origins of Phrase Structure. Doctoral dissertation, Massachusetts Institute of Technology, Cambridge

Svenonius, Peter (2000): Subject Positions and the Placement of Adverbials. In: Svenonius, Peter (ed.): Subjects, Predicates, and the EPP. Oxford: Oxford University Press. 203-246

Tsimpli, Ianthi Maria (1990): The Clause Structure and Word Order in Modern Greck. UCL Working Papers in Linguistics 2. 226-255

Ura, Hiroyuki (1994): Varieties of Raising and the Feature-Based Bare Phrase Structure Theory. MIT Occasional Papers in Linguistics 7. Cambridge: MITWPL

Ura, Hiroyuki (1996): Multiple Feature-Checking: A Theory of Grammatical Function Splitting. Doctoral dissertation, Massachusetts Institute of Technology, Cambridge

Uriagereka, Juan (1999): Multiple Spell Out. In Samuel D. Epstein and Norbert Hornstein (eds.), Working Minimalism. Cambridge, MA: MIT Press. 251-282

Zwart, C. Jan-Wouter (1992): Dutch Expletives and Small Clause Predicate Raising. In: Broderick, Kimberley (ed.): Proceedings of the 22nd Meeting of the North East Linguistic Society. Amherst, MA: GLSA, University of Massachusetts. 477-491

Zwart, C. Jan-Wouter (1993): Dutch Syntax. A Minimalist Approach. Doctoral dissertation, Rijksuniversiteit Groningen

Zwart, C. Jan-Wouter (1986): On the Relevance of Aspect to Middle Formation. Manuscript, Rijksuniversiteit Groningen

Zwart, C. Jan-Wouter (1998): Nonargument Middles in Dutch. Groninger Arbeiten zur germanistischen Linguistik 42. 109-128

Zwart, C. Jan-Wouter (2000): An Argument against Multiple Specifiers. Paper presented at WCCFL 19, University of California, Los Angeles. February 4-6, 2000

Zwart, C. Jan-Wouter (Forthcoming): Object Shift with Raising Words. Linguistic Inquiry

Kleanthes K. Grohmann

Zentrum für allgemeine Sprachwissenschaft,

Typologie und Universalienforschung

Jägerstr. 10-11

10117 Berlin

Germany

kleanthes@punksinscience.org 